between fundamental and applied research. He combined the "wache Neugier, den Schleier der Natur zu lüften" (awake curiosity to lift off the veil of Nature) with the objective of giving a solid base to application, and an education to engineers so that they could go on and develop practical devices $\left.{ }^{1}\right)$.

Barkhausen was an outstanding university teacher who tried always to achieve the utmost simplicity and clarity, however difficult the topic. He also had the type of personality that could form the mind and character of his students while still encouraging them to express their own indepen- dence and creativity. He was great humanist and a warm-hearted person, interested in the personal problems of his students and ready to help them when they were in need.

There is much that is of interest in the life and work of Barkhausen, in the man himself, his physics and also in how he saw the place of physics in Society and the responsibility of physicists for progress in technology.

For all these reasons, the Academy of Science of the DDR (of which Barkhausen was a member) and the Technical University of Dresden are celebrating the 100th an- niversary of his birth with a ceremony and scientific conference this month.

\section{BIBLIOGRAPHY:}

1. Lunze K. (Ed.) Festschrift der BarkhausenEhrung der Akademie der Wissenschaften der DDR und der Technischen Universität Dresden im Dezember 1981 (Berlin, Dresden) 1981.

2. Heinrich Barkhausen, "Das Problem der Schwingungserzeugung mit besonderer Berücksichtigung schneller elektrischer Schwingungen". Thesis, Göttingen, 1907.

3. Heinrich Barkhausen, "Die Probleme der Schwachstromtechnik" Dinglers Polytechnisches Journal, 92 (1911) 33/34 (also inclued in Ref. 1).

\title{
Computational Physics Group
}

The activities of the Computational Physics Group of the European Physical Society have, as objective, the sharing of experience and the dissemination of results of research into the application of computers to physics. Within this framework can be considered problems related to the computerization of experiments, data acquisition, interpretation of experimental data, data processing, theoretical calculations, as well as assistance in the design and utilization of physical instruments and facilities.

The main effort of the CPG is devoted to the organization of Conferences which may be general in character or concentrated on more specific aspects of computer applications in physics. In 1980, we had the Conference on Computing in High Energy and Nuclear Physics, held 9-12 September in Bologna, and recently, the Europhysics Conference on Vector and Parallel Processors, held 25-28 August in Chester. This was a general conference and covered the capabilities and potentials of modern, mostly large computers, and their impact on the development of physical research and applications.

Next year, 21-24 September 1982 in Warsaw, the Europhysics Conference organized by CPG in cooperation with the Institute of Nuclear Research, SwierkOtwock, Poland, and the Polish Physical Society will be devoted to more specialized topics. Entitled "Computing in Accelerator Design and Operations" it will cover the use of computers in design and digital control, and the application of accelerators in research, medicine and industry. Future CPG Conferences are to be devoted to Computing in Plasma Research, Software for Engineering Tools, etc.

Another line of CPG activities is the organization of Summer Schools in Computing in Physics. They are organized in cooperation with the Czechoslovak Union of Mathematicians and Physicists in beautiful, old castles so richly distributed throughout that country. The last in Stara Lesna, 18-29 May was devoted to the use of microprocessors in physics and was accompanied by a workshop on symbolic languages.

It is planned that the next Summer Schools held in odd years, possibly organized also by other national physical societies, will be devoted to the application of data base concepts in physics as well to other software engineering methods and tools, which could be applied in physics.

$A$ very interesting initiative of the $C P G$ is the encouragement it is giving to the editing of handbooks of formulae and computing methods used in various branches of physics. A number of possibilities for the publication of these handbooks, which would make them available at low cost to EPS members, are at present being stu- died. The first two handbooks will be devoted to High Energy Physics, and Atomic and Molecular Physics. People interested in taking part in such activities should contact the Computational Physics Group Board. Their efforts will be assisted and sponsored by the CPG.

Next year, on 20 September in Warsaw, a general meeting of the members of the Computational Physics Group will take place, where the programme of further activities will be discussed. Everyone working in the field of computational physics or interested in its development is urged to join the Computational Physics Group. Furthermore all members of the Group are asked to participate actively in the general meeting so as to influence the formulation of objectives.

R. Zelazny

\section{Plasma Physics Division}

On 14 September 1981, the Board of the Plasina Physics Division held its annual meeting in Moscow during the 10th European Conference on Controlled Fusion and Plasma Physics. The first regular General Assembly of the Division took place at the site of the Conference on 17 September. It is time therefore to report again on the affairs of the Division as was first done a year ago (Europhysics News, 11 (1980) 7/8).

Although this is not the proper place to give a major scientific appreciation, it should be said that the Conference showed that there is steady progress in all fields of fusion-related plasma physics. Contributions came from colleagues from all over the world and, in particular, the Conference allowed us to gain a detailed insight into the work going on in the Soviet Union. In tokamaks, rapid progress has been achieved in divertor experiments and studies of the plasma edge, confirming the effectiveness of divertors in reducing the concentration of metal ions in the discharge. An improvement in plasma confinement and more detailed analyses of its parametric dependence were also reported and electron cyclotron heating of plasma has been demonstrated on a larger scale. Both theoretical analyses and experimental work have improved our understanding of stellarators, the reversed-field pinch and the bumpy torus and the dynamics and the structure of the plasma focus have been elucidated in more detail. Experiments in the tandem mirror configuration were reported in which the ideal MHD pressure limit was exceeded. Plasma compression by intense laser beams is studied with new, more powerful devices. Also new ideas on the muon fusion of DT were reported which suggest that this scheme might be more than just a curiosity. A highlight of the Conference was P. L. Kapitza's report on his work in thermonuclear fusion research. It is regrettable that some very relevant results obtained recently in western European laboratories were not presented at the Conference.

Turning now to matters discussed at the meeting of the Board and in the General Assembly: First, to prepare the 11th European Conference on Controlled Fusion and Plasma Physics, to be held 5-9 September, 
1983 at Aachen, a Programme Committee has been set up, chaired by E. Hintz (Jülich). Members are A. Gibson (Abingdon), J. Jacquinot (Fontenay-aux-Roses), D.D. Ryutov (Novosibirsk), F. Troyon (Lausanne), and R. Wienecke (Stuttgart). As the format of the Moscow Conference was considered to be very satisfactory, it was agreed to follow the same lines at Aachen. The Organizing Committee of the Conference will be chaired by G. H. Wolf (Jülich).

The EPS Council has approved the application of a new formula for the submission of contributed papers to the Conference. Colleagues who are not individual members of EPS nor members of EPS Member Societies nor on the staff of organizations which are Associate Members of EPS, will need sponsorship for submitting a contribution. This can be given either by an individual member of EPS (with an upper limit of two papers per individual member) or by a Member Society. The introduction of this rule derives from the conviction of the Board that EPS membership must be made more attractive. The Divisional Conference at Aachen is taking place in the week following the International Conference on lonization Phenomena in Gases at Düsseldorf, so that participation in both events will be very much eased in 1983

A question which received much attention at both this meeting of the Board and in the General Assembly of EPS is that of free access of members to the Conferences organized by the Division. There was complete agreement on all sides that this was an established right, but it was recognized that there are a number of practical points connected with this right which have to be made more precise.

Although the number of members of the Division has somewhat increased during the past year (it totals now about 270), the situation is still far from being satisfactory. Continuing efforts of all members are therefore necessary to convince more colleagues to join EPS and the Division. Only with an increasing number of individual members will EPS and the Division be able

\section{Official Announcements}

In Istanbul, Council gave tacit agreement to the principle that the unit fee should follow the inflation experienced in Switzerland. As Council will meet only once in 1982 it will be invited at its meeting on 1-2 April 1982 to approve the following:

In accordance with the provisions of Rules 34 and 35 of the By-Laws, the Council agrees that the Unit fee shall be raised from Sw.Fr. 9. - to Sw.Fr. 10.from 1 January 1983.

\section{Divisional Boards}

The following members have been coopted on to Divisional Boards:

Condensed Matter Division

$$
\begin{aligned}
& \text { H. Grimmeiss, Lund } \\
& \text { V. Heine, Cambridge } \\
& \text { E. Mooser, Lausanne } \\
& \text { F. Mueller, Nijmegen }
\end{aligned}
$$

\section{Nuclear Physics Division}

G. Tibell, Gustaf Werners Inst., Uppsala

I. Ulehla, University, Prague

H. Zingl, University, Graz

New Chairman of the Nuclear Physics Division is: P. von Brentano, Cologne following the resignation of $\mathrm{V}$. Meyer.

to extend its activities and give better service to the physics community in Europe.

A number of loose contacts between the Division and the Plasma Physics Sections of the EPS Member Societies have been established, but in this field also further efforts are necessary.

Unfortunately, it was not possible in Moscow to constitute the new Board of the Plasma Physics Division whose term starts on 1 January 1982, because only a very small number of its members were able to participate in the meeting that had been arranged. Elections to the Board have recently taken place (see Europhysics News, 12, (1981) 8/9 p. 12) and the constitution of the Board is now being established by written procedure. The outcome will be communicated as soon as possible.

\section{F. Engelmann}

At the meeting of Council held in Istanbul on 6 Sept. 1981, it was agreed that the Executive Committee should present proposals to provide for the admission to the EPS, of physicists who are members of other major regional physical societies with which Council has agreed to collaborate.

In accordance with this instruction, Council will be invited to approve at its next meeting on 1-2 April 1982, the definition of a new category of individual membership, by agreeing to the following changes to the Constitution and By-laws.

\section{Constitution}

ARTICLE 4

Add:

d) individuals who are members of a society or group which is not an Ordinary Member, Category 4b) but has been approved by Council as a Collaborating Society.

ARTICLE 16

Subsection bl, replace line 2 by:

individual members of Categories a), c) and d) mentioned in Article 4, as

\section{By-Laws}

RULE 1

Add:

or a Collaborating Society.

RULE 19

Replace in line 2, Article 4a) and c) by: Article 4a), c) and d)

RULE 35

Add:

d) Individual Ordinary Members, Constitution Article $4 \mathrm{~d}$, who are thus also members of a Collaborating Society.

Such number of units as decided by Council for each Collaborating Society

Note: the two paragraphs in RULE 35 are positioned opposite each other.

RULE 36

Replace by:

Fellows shall pay as Individual Ordinary Members, Rule 35a), c) or d).

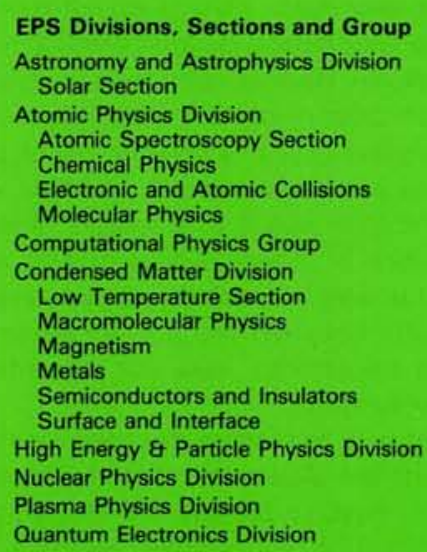

Europhysics News is the official journal of the European Physical Society that comprises 28 National Societies, Academies and Groups, over 3000 Individual Ordinary Academies and Groups, over 300 individual Ordinary of EPS are the General Meeting, Council and an elected Executive Committee responsible for detailed policy. EPS promotes the collaboration of physicists throughout Europe and encourages all aspects of international exchange in physics. EPS awards scholarships for research and studies and makes arrangements for tea. ching abroad. EPS publishes, in addition to Europhysics News, Europhysics Conference Abstracts, the Procee dings of its General Conferences and (with the I.O.P.) the European Journal of Physics. Individual Ordinary Members receive Europhysics News (subscription for non-members: $82 \mathrm{Sw}$. Fr./al, substantial rebates on publications and pay reduced fees at conferences Application for membership is made through the perApplication for membership is made through the permembers of a National Society will be Sw.Fr. 36 in 1982

\section{Editor: E.N. Shaw}

Meetings Compilation: W.S. Newman

Editorial Board:

K. Appert, A. Baratoff, G.J. Béné,

G.R. Macleod, A. Maeder, J. Muller

Editorial and Advertising Office at the EPS Secretariat.

Address: EUROPEAN PHYSICAL SOCIETY P.O. Box 69 , CH-1213 Petit-Lancy 2 Switzerland

Telephone: Geneva (22) 931130

Telex: 23455 alarm ch

Cables: europhys genève

Printed by: Pfirter frères SA

CH-1213 Petit-Lancy/Switzerland 